Background.-Cerium dioxide nanoparticles $\left(\mathrm{CeO}_{2} \mathrm{NP}\right)$ have antioxidant properties and also can alter membrane potential in mitochondria influencing cell respiration. In this study we check the idea that $\mathrm{CeO}_{2} \mathrm{NP}$ adsorbed on the silicon base has counter inflammatory, antioxidant and metabolic effects and can be possibly applied in pneumonia treatment.

Methods.- Thirty-six Wistar male rats, 5 months old, 250-290 g were divided in five groups: 1) intact animals; 2) i/p saline injection; 3) $\mathrm{CeO}_{2} \mathrm{NP}$ treatment; 4) experimental pneumonia (i/p LPS injection, $1 \mathrm{mg} / \mathrm{kg}$ ); 5) experimental pneumonia treated by $\mathrm{CeO}_{2} \mathrm{NP}(2.5 \mathrm{mg} / \mathrm{kg})$. Pulmonary ventilation and gas exchange were measured four times: before and 1,3 and $24 \mathrm{~h}$ after LPS injection. The mRNA of TNF- $\alpha$, Il- 6 , and CxCL3 were determined by RT-PCR. ROSgeneration in blood plasma and lung tissue homogenate was measured by means of lucigenin- and luminol-enhanced chemiluminescence.

Results.-Endotoxaemia in the acute phase was associated with essential inhibition of metabolism: gradual decrease of $\mathrm{V}_{\mathrm{E}}$ (by $72 \%$ ) and $\mathrm{VO}_{2}$ (by 62\%) 24 hour after LPS injection; pathological changes in lung morphology; enhanced expression of CxCL3 (by 68\%); increase of ROS generation in blood (by 660\%) and lungs (in $33 \%$ ).

LPS-injected rats treated with $\mathrm{CeO}_{2} \mathrm{NP}$ did not demonstrate any $\mathrm{V}_{\mathrm{E}}$ and $\mathrm{VO}_{2}$ reduction 1 hour after LPS-injection and increase of $\mathrm{V}_{\mathrm{E}}$ (by 25\%) and $\mathrm{VO}_{2}$ (by $20 \%) 3$ hours after injection; this effect remained 24 hours after injection.

It should be noted that $\mathrm{CeO}_{2} \mathrm{NP}$ treatment of control rats increased $\mathrm{V}_{\mathrm{E}}$ by $20 \%$ and $\mathrm{VO}_{2}$ by $45 \%$ in comparison with first measurement after each introduction of the substance.

Treatment of LPS-injected rats with $\mathrm{CeO}_{2} \mathrm{NP}$ has led to diminishing in lung morphology pathological deviations; significant decrease of the expression of inflammatory markers: CxCL33 (in 7.1 times, p $<0.01$ ), Il-6 (in 3.5 times, $\mathrm{p}<0.05$ ) and TNF- $\alpha$ (in 2 times, $\mathrm{p}=0.05$ ); significant reducing of ROS generation in blood (in 2.7 times, $\mathrm{p}<0.05$ ), and lung tissue homogenate (in 1.3 times $\mathrm{p}<0.05)$.

Conclusions.- $\mathrm{CeO}_{2}$ NP significantly reduces morphological and functional pulmonary damage in course of experimental acute pneumonia. Discussing mechanism of this effect we propose two suggestions. First: $\mathrm{CeO}_{2} \mathrm{NP}$ is powerful antioxidant, which protects lung tissue and, possibly, inhibits synthesis of cytokines. Second: treatment with $\mathrm{CeO}_{2} \mathrm{NP}$ significantly accelerate metabolism and gives additional vigor to cells suffering with pneumonia.

\section{Life in High-Altitude Conditions}

Thuppil Venkatesh, PhD, FACBI

Profesor Emeritus, Dept of Biochemistry, St. John's Medical College, Bangalore, India

I have always accepted and endorsed both Prof. Dr. Gustavo Zubieta-Castillo (Sr) and Prof. Dr. Gustavo Zubieta-Calleja (Jr) whenever they mentioned that life is possible on top of Mt Everest. I never doubted. I have a lot of supporting evidence which I wish to share with the rest of the world, during this meeting at very high altitude in Chacaltaya $(5230 \mathrm{~m})$ where I deliver my talk for the second time. Life does exist at extreme conditions of heat, pressure, temperature, radiation etc. We have functional life at the deepest part of the sea and at very high altitude. Life started at the bottom of the sea and birds fly for long hours at very high altitudes during their migration. People migrated to live and reproduce at high altitudes. The secret of life adaptation is not well understood. Scientists have designed their studies to find out the problems faced during their adaptation. Limited efforts are made to realize how life has sustained for long periods of time at extreme conditions. The most common household pests, cockroaches, have survived severe radiation, heat, and cold and even toxic pesticides, to which they adapt and can therefore not be eliminated. Plants which normally grow at a particular rate under normal conditions, are found growing at a higher rate when their life is threatened, as noted in young mango plants when pruned, they flower and yield fruit earlier. We are aware of the longevity in plants when they are bonsaied. Similar life prolongation is noted in humans and animals under hypoxic conditions. Longevity of life under hypoxic conditions is well established and it seems evident that high altitude residents have a healthy form of life. Lowlanders under hypoxic conditions and highlanders under hyperbaric conditions, as presented by Prof. Dr. Gustavo Zubieta-Calleja, will have initial problems (peripheral edema, somnolence and other changes), which get adjusted. On long stays, with generations living in those environments, there will be a genetic adaptation, which is applicable to all forms of life. Physical and mental performance improves at higher altitudes. Hypoxia makes other dormant parts of the human brain function, and hence great philosophers and religious giants frequently visited high altitudes. When these environments are altered by any manmade developments, it hampers the process of natural adaptation. Many toxins are now found causing environmental damage at various levels. This is evidenced by the unreasonable usage of medication. Living in harmony with nature seems to be the ultimate solution. The effect seems to be more evident on life at high altitudes. Let us preserve high altitude conditions for better health, for quality longevity. Let the dream of the Parvatha Guru (Mountain Guru), Gustavo Zubieta-Castillo Sr., come true.

\section{Rearrangement of Neuroendocrine Systems in the Mountains}

Sadykova Gulnura, MD; Dzhunusova Gulnara, MD

Institute of Mountain Physiology National Academy of Sciences, Kyrgyz Republic

The aim of this research was to study the functional state of the anterior pituitary, thyroid, adrenal, and reproductive glands and their relationship with chronic exposure to high altitude. Studies were conducted in high altitudes inhabitants of the Tien-Shan $(1200 \mathrm{~m}, 2800 \mathrm{~m}, 3600 \mathrm{~m})$. Adrenocorticotropic hormone (ACTH), cortisol, catecholamines, thyroid, and sex hormones were determined by immunosorbent and spectrofluorometric methods. Normal hormone levels for sea level inhabitants were used for comparison.

Increased cortisol levels in mountaineers $(\mathrm{M})(2800 \mathrm{~m})$ may reflect a reduction in reserve capacity of the pituitary-adrenocortical system and the formation of their chronic condition or incomplete adaptation, or the continuing adaptation to the environment in a number of successive generations. Reduced activity of the pituitary-adrenocortical system in high altitude residents (HAR) at $3600 \mathrm{~m}$ is a consequence of the harsh weather conditions, narrowing the boundaries of the organism's adaptation and facilitating economical and appropriate regulation.

High altitude residents at $2800 \mathrm{~m}$ and $3600 \mathrm{~m}$ (when compared to the normal hormone levels and data of low mountain residents at $1200 \mathrm{~m}$ ), presented a predominance of the mediator activity of the hormone sympathetic-adrenal system, showing an increased secretion of norepinephrine and dopamine, and a decreased secretion of epinephrine. Increased levels of norepinephrine are associated with its decreased metabolism and reserves, providing constant catecholamines that create the preconditions for a stable and long-term work of the body, providing an adequate state of physiological function. Feeding habits (prevalence of carbohydrates and fats in food $\mathrm{M}$ and HAR) also lead to the activation secretion of norepinephrine, which leads to intensive use of the biological mediator precursor, dopamine, as evidenced by its high level in residents at both altitudes. This change in optimum reserve of catecholamines promotes an accelerated restoration of catecholamine levels.

Prolonged exposure to high altitude hypoxia induces contrasting changes in thyroid hormone levels. The mountaineers $(2800 \mathrm{~m})$ are found close to the low values of normal TSH levels, whereas thyroid hormones tend to increase. The increase in T3 and T4 levels, while maintaining the basic concentration of TSH or small hyperthyroidism, seem necessary to adapt to the extreme conditions of high mountains. Increased levels of $\mathrm{T}_{4}, \mathrm{TSH}$ and norepinephrine, with a decreased secretion of $\mathrm{T}_{3}$ in HAR $(3600 \mathrm{~m})$, reflect an additional reaction on the PTS factor constant exposure to cold in the mountains. Low values of $\mathrm{T} 3$ without changes in $\mathrm{TSH}$ and $\mathrm{T}_{4}$ levels are explained by the influence of cold

The detected levels of testosterone in male HAR $(3600 \mathrm{~m})$ show the adverse effects of environmental factors, and reduced levels of progesterone (89\%) indicate a hard endocrine function of women M $(2800 \mathrm{~m})$, on the mobilization of the strategic reserve endocrine system. However, the decreased functional activity of the sex glands does not exceed the boundaries of conventional indicators, which are a reflection of the body's resistance.

Conclusion: Features of endocrine systems in high-population of Tien-Shan include reduced activity of the pituitary-adrenocortical system in the organism, and economical operation, which allows for normal life, work and heavy physical activities in the specific conditions of the mountains. The parameters of endocrine status should be assessed only in relation to normal population values.

Why is it Not Possible to Predict, Through Tests at Sea Level, Who Will Develop AMS?

Gustavo Zubieta-Calleja, MD; Natalia Zubieta DeUrioste

High Altitude Pulmonary and Pathology Institute (IPPA), La Paz, Bolivia 